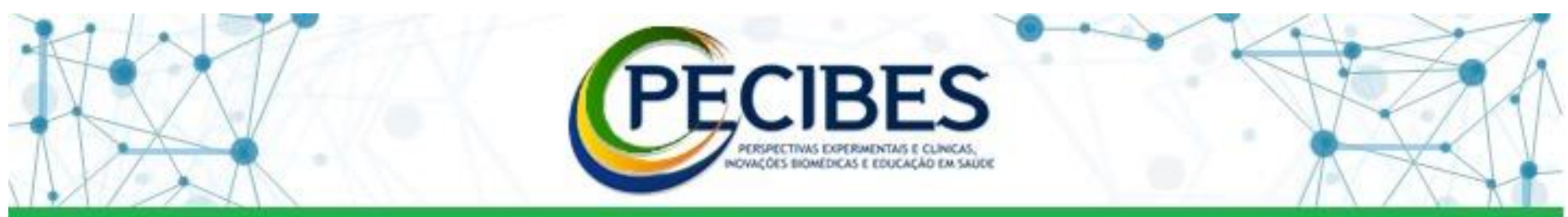

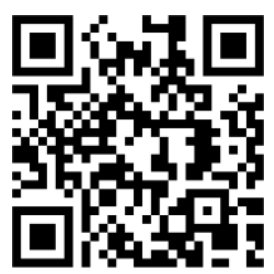

http://www.seer.ufms.br/i ndex.php/pecibes/index

\footnotetext{
*Autor correspondente: Joice Elica Espindola Paes

Ozelame, Universidade Federal de Mato Grosso do Sul - UFMS. E-mail do autor:joeozelame@g mail.com
}

Descritores: Mortalidade materna. Mulheres. Idade fértil. Cuidado Prénatal. Promoção da saúde.

Key-words:

Maternal mortality. Women. childbearing age. Prenatal care. Health promotion.

\section{Mortalidade de mulheres em idade fértil com ênfase na mortalidade materna no Mato Grosso do Sul- 2015 a 2019}

Mortality of women of childbearing age with emphasis on maternal mortality in Mato Grosso do Sul2015 to 2019

Joice Élica Espindola Paes Ozelame ${ }^{1}$, Alecsandra Fernandes da Silva ${ }^{2}$, Maria Betina Leite de Lima ${ }^{3}$, Nicholas Ocuda Henrique de Lima ${ }^{4}$

1. Mestre em Enfermagem e Residente em Enfermagem Obstétrica, Universidade Federal de Mato Grosso do Sul, Campo Grande, MS, Brasil

2. Enfermeira. Residente em Enfermagem Obstétrica, Universidade Federal de Mato Grosso do Sul, Campo Grande, MS, Brasil

3. Enfermeira. Residente pelo Programa de Residência Multiprofissional: Atenção ao Paciente Crítico. Universidade Federal de Mato Grosso do Sul, Campo Grande, MS, Brasil

4. Nutricionista. Residente pelo Programa de Residência Multiprofissional: Atenção ao Paciente Crítico. Universidade Federal de Mato Grosso do Sul, Campo grande, MS, Brasil

Introdução: A reflexão acerca dos indicadores epidemiológicos de óbitos de mulheres em idade fértil e óbitos permite a avalialção da cobertura e da qualidade dos serviços de saúde, sendo um indicador sensível referente os aspectos que influenciam na saúde associados à gestação e as suas implicações na saúde da mulher. Objetivo: Descrever as características epidemiológicas dos óbitos de mulheres em idade fértil e óbitos maternos no Mato Grosso do Sul e verificar o cumprimento do $3^{\circ}$ objetivo dos Objetivos do Desenvolvimento Sustentável (ODS). Método: Trata-se de um estudo transversal e descritivo, com base em dados secundários do DATASUS-TABNET, referentes ao total de óbitos de mulheres em idade fértil e maternos de 2015 a 2019 no Mato Grosso do Sul. A coleta de dados ocorreu de agosto a setembro de 2021. Os dados foram analisados por meio de estatística descritiva com o uso de medidas de tendência central e dispersão e pelo cálculo da Razão de Mortalidade Materna (RMM), além do teste de associação Qui-quadrado ( $\mathrm{s}<=0,05)$. Destaca-se a dispensa do Termo de Consentimento Livre e Esclarecido (TCLE). Resultados: O ano de 2015 teve a maior RMM (70,2/100mil nascidos vivos), enquanto a taxa de mortalidade entre mulheres em idade fértil foi maior em 2016 (37,8 óbitos/100 mil habitantes). 2017 foi o ano de menor ocorrência da mortalidade materna (46,9/100mil nascidos vivos) e da mortalidade entre mulheres em idade fértil (30,8 óbitos/100 mil habitantes). Não houve redução das taxas de mortalidade. Verificou-se associação estatisticamente significativa entre escolaridade $(\mathrm{p}=0,0262)$, faixa etária $(\mathrm{p}=0,0038)$ e cor/raça $(\mathrm{p}=0,0001)$ com a ocorrência do óbito materno. Conclusão: A mortalidade entre mulheres em idade fértil e materna mostrou pouca variação na sua ocorrência de 2015 a 2019, e esta última não atingiu a meta de 30 óbitos/ 100 mil nascidos vivos estabelecida para o Brasil pelos ODS. 